\title{
Perception by 2-month-old infants of glide contrasts in multisyllabic utterances
}

\author{
PETER W. JUSCZYK, HEATHER COPAN, and ELIZABETH THOMPSON \\ Dalhousie University, Halifax, Nova Scotia B3H 4JI, Canada
}

\begin{abstract}
Several aspects of the 2-month-old's perception of a phonetic contrast between glides in multisyllabic utterances were explored with the high-amplitude sucking paradigm. First, do infants perceive contrasts between glides in the initial (e.g., YADA vs. WADA) and medial positions (e.g., DAYA vs, DAWA) of multisyllabic utterances? Second, are infants more likely to perceive these contrasts between stressed or unstressed syllables? Our results suggest the following: (1) 2-month-olds are sensitive to place-of-articulation differences between glides in both the initial and medial positions of multisyllabic utterances; (2) positioning stress on the syllables to be discriminated had little or no effect on the infants' ability to perceive the contrast; (3) there was no indication that infants were any more sensitive to the contrast in the initial position than in the medial position. Our findings were in complete agreement with those observed previously for infant's perception of stop consonant differences in multisyllabic utterances (Jusczyk \& Thompson, 1978).
\end{abstract}

Knowledge of the perceptual capacities which we possess for analyzing speech sounds is crucial to our understanding of how we successfully decode language. While speech comprehension undoubtedly involves a variety of processes and strategies (such as those dealing with syntactic and semantic constraints), our speech perceptual capacities provide at least a lower limit on our ability to analyze the speech signal. One of the chief aims of infant speech perception research has been to provide information about the nature of these basic perceptual capacities. To achieve this end, infant speech perception research must focus not only on the variety of contrasts which infants are capable of making, but also on how the infant's discriminative capacities are affected by various aspects of the phonetic context. In the past few years, progress has been made in both of these areas. Thus, with respect to the variety of contrasts that infants can discriminate, evidence now exists for the following kinds of distinctions: voicing (Eilers, 1977; Eimas, Siqueland, Jusczyk, \& Vigorito, 1971; Lasky, Syrdal-Lasky, \& Klein, 1975; Streeter, 1976), place-of-articulation (Eimas, 1974; Jusczyk, 1977; Morse, 1972; Miller, Morse, \& Dorman, 1977), liquids (Eimas, 1975), fricatives (Holmberg, Morgan,

An earlier version of this paper was presented at the 94th Meeting of the Acoustical Society of America, Miami Beach, December 16, 1977. This research was supported by grants to the first author from the National Research Council and from the Faculty of Graduate Studies, Dalhousie University. The authors wish to express their gratitute to Dr. Alvin M. Liberman and the staff of the Haskins Laboratories for their generosity in making facilities available for the preparation of stimulus materials. Also, our sincere thanks are extended to the staff and administrators of the Grace Maternity Hospital for their support of this research.
\& Kuhl, Note 1), stop/glide/vowel (Hillenbrand, Minifie, \& Edwards, Note 2), oral/nasal (Trehub, 1976; Eimas \& Miller, Note 3), stridency (Trehub, 1976), and vowels (Swoboda, Morse, \& Leavitt, 1976; Kuhl, Note 4).

The picture which emerges from studies of how infants' discriminative capacities are affected by the phonetic context is less clear. There is evidence with respect to single-syllable utterances that infants can discriminate syllable-final contrasts between stops (Eilers, 1977; Jusczyk, 1977) and between certain fricatives (Eilers, 1977). Similarly, investigations with multisyllabic stimuli generally have shown infants to be capable of detecting certain stop consonant contrasts occurring in the medial as well as initial position of the utterance (Jusczyk \& Thompson, 1978; Trehub, Note 5; Williams, Note 6). ${ }^{1}$ For instance, Jusczyk and Thompson (1978) found that place-of-articulation contrasts were distinguished as readily in medial position as they were in initial position. Moreover, contrasts between unstressed syllables were no more difficult for infants than those between stressed syllables. Williams (Note 6) has reported essentially the same results for stimuli in which a silent closure interval was present between the first and second syllables (as was the case with the Jusczyk $\&$ Thompson stimuli). On the other hand, in a case in which the silent closure interval was absent (instead, continuous glottal pulsing occurred during this period), Williams' infants did not discriminate a place-of-articulation contrast in the medial position. In discussing this result, Williams suggested that the period of continuous glottal pulsing may have detracted from the abruptness of the syllable onset (thus presumably masking the formant transition 
information available at the onset of the second syllable). If so, then the presence of a silent closure interval may be necessary for infants to perceive contrasts in the medial position.

Thus far, investigators exploring the infant's perception of multisyllabic utterances have limited their examinations to contrasts between stop consonants. In order to determine whether findings from these studies are representative for other kinds of phonetic contrasts, we chose to examine the infant's perception of glides ([w] and [y]) in multisyllabic contexts. As with most other place-of-articulation contrasts, the distinction between [w] and [y] is cued by differences in the nature of the second- and third-formant transitions. In the vowel context [a], [w] has a rising second formant and a flat third formant, while [y] has falling second and third formants. In this respect, the glides [w] and [y] behave similarly to the stops [b] and [d], respectively. In fact, the chief feature which distinguishes the glides from the stops is the duration of the formant transitions (glide transitions are approximately three times longer than those of stops).

The perception of glides was of interest to us for a number of reasons. First of all, when the glides [w] and $[\mathrm{y}]$ occur in the middle of multisyllabic strings, there is no silent closure period to mark them acoustically as there is typically with stop consonants. The absence of a silent closure interval for glides is a direct result of the way in which these sounds are articulated. Unlike stop consonants which require a complete closure of the vocal tract, glides are produced by narrowing the tract at particular locations. Consequently, rather than being marked by abrupt onsets, glides tend to flow directly from and to adjacent phones in the speech stream. Thus, given Williams' (Note 6) findings, the fact that glides lack a silent closure interval may mean that infants might not discriminate them in medial positions of utterances. A second reason for our interest in glides was the possibility that stress placement might affect the infant's ability to discriminate between them. A syllable can be stressed by increasing, either singly or in combination, its pitch, intensity, and duration relative to other syllables nearby (Fry, 1958; McClean \& Tiffany, 1973; Morton \& Jassem, 1965). Stress, then, may serve to call attention to a particular syllable. If so, then stress may play an important role in language acquisition. Indeed, the language-learning child often omits unstressed syllables in his productions, and a number of developmental psycholinguists have suggested that stress is a factor in which words a child learns first (Blasdell \& Jensen, 1970; Brown \& Fraser, 1963; Miller \& Ervin, 1964). Nevertheless, the role which stress may play in infant speech perception is still largely unexplored. While a number of investigators have shown that infants can detect differences in stress placements (e.g., Jusczyk \& Thompson, 1978; Spring \& Dale, 1977), Jusczyk and Thompson (1978) did not find an interaction between stress placement and the discrimination of stop consonants. However, it is possible that the rather abrupt onsets of stops are sufficient in themselves to mark these sounds quite prominently in the speech stream. Given that glides have much more gradual onsets, stress may affect their discriminability for infants. Thus, glide contrasts between unstressed syllables might not be as detectable as those between stressed syllables. Finally, while a number of studies have shown that infants discriminate place-ofarticulation differences between stops (e.g., Eimas, 1974; Jusczyk, 1977; Morse, 1972), the results of studies with fricatives are equivocal (Eilers, Wilson, \& Moore, in press; Holmberg, Morgan, \& Kuhl, Note 1). Thus, we wished to determine if infants are sensitive to place-of-articulation differences between glides.

In the present study, we address two questions. First, do infants discriminate contrasts between glides in initial ([Wada] vs. [Yada]) and medial ([Dawa] vs. [Daya]) positions of multisyllabic utterances? Second, are infants more likely to discriminate these contrasts between stressed or unstressed syllables? Accordingly, we compared the infant's ability to detect the same contrast in both stressed (e.g., [Dawá] vs. [Dayá]) and unstressed ([Dáwa] vs. [Dáya]) syllables.

\section{METHOD}

\section{Procedure}

Each infant was tested individually in a small laboratory room. The infant was placed in a reclining chair which faced a rearprojection screen approximately $.5 \mathrm{~m}$ away. An image of a man was displayed on the screen for the entire test session. The projection screen was situated just above a loudspeaker through which the test stimuli were played. Each infant sucked on a blind nipple which was held in place by one of the experimenters who wore headphones and listened to recorded music throughout the test session. A second experimenter in an adjacent room monitored the apparatus.

The experimental procedure was a modification of the highamplitude sucking technique developed by Siqueland and De Lucia (1969). For each infant, the high-amplitude sucking criterion and the baseline rate of high-amplitude sucking were established prior to the presentation of any stimuli. The criterion for highamplitude sucking was adjusted so as to produce rates of 15 to $30 \mathrm{sucks} / \mathrm{min}$. After a baseline rate was established, the presentation of stimuli was made contingent upon the rate of highamplitude sucking. Since the stimuli were $650 \mathrm{msec}$ in duration and a 750-msec interstimulus interval was used, a maximum of one stimulus was presented every $1.4 \mathrm{sec}$. If the infant produced a burst of sucking responses with interresponse times of less than $1.4 \mathrm{sec}$, then each response did not produce one presentation of the stimulus. Rather, the timing apparatus was reset so as to provide continuous auditory feedback until $1.4 \mathrm{sec}$ after the last response of the sucking burst.

The criterion of satiation to the first stimulus was a decrement in sucking rate of $25 \%$ or more over 2 consecutive minutes com- 
pared to the rate in the immediately preceding minute. At this point, the auditory stimulation was changed without interruption by switching channels on the tape recorder. For infants in the experimental conditions, the change resulted in the presentation of a second acoustically distinct stimulus. For infants in the control condition, the channels on the tape recorder were switched, but no acoustic change was made. The postshift period lasted for $4 \mathrm{~min}$. The infant's sensitivity to the change in auditory stimulation was inferred from comparisons of the response rates of subjects in the experimental and control conditions during the postshift period.

\section{Stimuli}

So that we might closely approximate those features of naturally produced bisyllabic utterances such as stress patterns and spacing between syllables, our speech stimuli were produced at the Haskins Laboratories in the following manner. Naturally produced speech samples were recorded on auditory tape. The waveform data was sampled at a rate of $10 \mathrm{kHz}$ and bandpassed at $90 \mathrm{~Hz}$ to $4.9 \mathrm{kHz}$. Spectrum data was provided as the output of a Ubiquitous spectrum analyzer at a rate of 128 samples per frequency span (approximately $4.9 \mathrm{kHz}$ bandwidth), repeated every $12.8 \mathrm{sec}$. Wideband filtering $(240 \mathrm{~Hz})$ was applied to the spectrum data and a peaks extraction routine (CONVERT) was used to provide values for the parameters of the OVE IIIc serial synthesizer. The resulting synthetic utterances were then digitized, using the Haskins PCM system (Cooper \& Mattingly, 1969). The output of the PCM system was then used to prepare the audio tapes employed in this experiment.

Eight different synthetic bisyllabic stimuli were created (Dáwa, Dawá, Dáya, Dayá. Wáda, Wadá, Yáda, Yadá). Each stimulus consisted of one stressed and one unstressed syllable. For half of the stimuli, the stressed syllable was first (Dáwa, Dáya, Wáda, Yáda). For the other half, the unstressed syllable was first (Dawá, Dayá, Wadá, Yadá). In order to stimulate the closure of a stop consonant in medial positions, when [da] occurred as the second syllable, it was preceded by a 78-msec silent interval. No such period was present when either [wa] or [ya] appeared as the second syllable. Instead, continuous voicing occurred at a level $12 \mathrm{~dB}$ below that of the vowel steady state.

Stressed syllables had durations of $364 \mathrm{msec}$ and fundamental frequency (pitch) contours which began at $117 \mathrm{~Hz}$, peaked $130 \mathrm{msec}$ later at $132 \mathrm{~Hz}$, then fell gradually to $100 \mathrm{~Hz} .^{2}$ By contrast, the unstressed syllables had durations of $208 \mathrm{msec}$, and fundamental frequency contours which began at $106 \mathrm{~Hz}$, peaked $65 \mathrm{msec}$ later at $117 \mathrm{~Hz}$, and declined gradually to $106 \mathrm{~Hz}$. In addition, the maximum amplitude of the stressed syllables was $5 \mathrm{~dB}$ greater than that of the unstressed ones. Table 1 indicates the nature of the formant frequencies and transitions of our syllables.

Table 1

Formant Frequencies and Transition Durations (in Msec) of Each Syllable

\begin{tabular}{ccccc}
\hline & & $\begin{array}{c}\text { Onset } \\
\text { Frequency }\end{array}$ & $\begin{array}{c}\text { Steady-State } \\
\text { Frequency }\end{array}$ & $\begin{array}{c}\text { Transition } \\
\text { Duration }\end{array}$ \\
\hline \multirow{6}{*}{$\mathrm{Da}$} & F1 & 259 & 777 & 50 \\
& F2 & 1770 & 1139 & 65 \\
& F3 & 2413 & 2245 & 65 \\
Wa & F1 & 259 & 777 & 150 \\
& F2 & 658 & 1139 & 150 \\
& F3 & 2245 & 2245 & \\
Ya & F1 & 259 & 777 & 150 \\
& F2 & 1796 & 1139 & 150 \\
& F3 & 2502 & 2245 & 150 \\
\hline
\end{tabular}

\section{Design}

In the present study, each infant was seen for one session. Twelve subjects were assigned randomly to each of five groups. Group I was tested for the ability to detect the [w]-[y] distinction when it occurred in the second unstressed syllable of a two-syllable utterance (i.e., [Dáwa] vs. [Dáya]). For subjects in Group II, the [w]-[y] contrast also was present in the second syllable, but this time the syllable was stressed (i.e., [Dawá] vs. [Dayá]). Group III received the $[w]-[y]$ contrast between the initial unstressed segments of a two-syllable utterance (i.e., [Wadá] vs. [Yadá]). Group IV was also tested on this distinction but in the context of initial stressed syllables (i.e., [Wáda] vs. [Yáda]). Finally, subjects in the control condition, Group V, were randomly assigned one of the eight bisyllable stimuli for the entire session (e.g., [Dáwal vs. [Dáwa]). For each of the groups, the presentation order of stimuli was counterbalanced across subjects.

\section{Apparatus}

A blind nipple was connected to a Grass PT5 volumetric pressure transducer which, in turn, was coupled to a Type DMP-4A Physiograph. A Schmitt trigger provided a digital output of criterial high-amplitude sucking responses. Additional equipment included a Teac 2340 SX tape recorder, a Harman-Kardon A-402 power amplifier, an Ads 200 loudspeaker, a Lafayette 100-sec timer, a power supply, two relays, a counter, and a Physiograph dc preamplifier. Each criterial response activated the 100 -sec timer for a 1.4-sec period or restarted the period. Auditory stimulation at a level of $75 \pm 2 \mathrm{~dB}$ (A) SPL (approximately $15 \mathrm{~dB}$ above the background noise level caused by the ventilation system) was available to the infant whenever the timer was in an active state.

\section{Subjects}

The subjects were 60 infants, 32 males and 28 females. Mean age was 7.3 weeks (range: 6 to 10 weeks). In order to obtain 60 subjects for our study, it was necessary to test 120 . Subjects were excluded from the study for the following reasons: crying (37\%) or failing asleep $(35 \%)$ prior to shift, ceasing to suck during the course of the experiment (i.e., 2 consecutive minutes with less than 2 sucks $/ \mathrm{min})(8 \%)$, failure to maintain a minimum criterial sucking rate of 15 responses/min during the satiation period $(3 \%)$, equipment failure $(5 \%)$, experimenter error $(5 \%)$, and miscellaneous (vomiting, bowel movements, etc.) $(7 \%)$.

\section{RESULTS}

Figure 1 displays the mean number of highamplitude sucking responses as a function of minutes and experimental groups. For purposes of statistical comparisons, we examined each subject's rate of sucking during five intervals: baseline minute, third minute before shift, average of Minutes 1 and 2 before shift, average of Minutes 1 and 2 after shift, and average of all $4 \mathrm{~min}$ after shift. Difference scores were then calculated for each subject for each of the following rate comparisons: (1) acquisition of the sucking response-third minute before shift less baseline; (2) satiation-third minute before shift less average of the last $2 \mathrm{~min}$ before shift; (3) release from satiation-average of first 2 min after shift less average of last $2 \mathrm{~min}$ before shift; (4) release from satiation for full $4 \mathrm{~min}$-average of $4 \mathrm{~min}$ after shift less average of last 2 min before shift.

As is usually the case in studies employing this procedure, subjects in all sessions acquired the condi- 


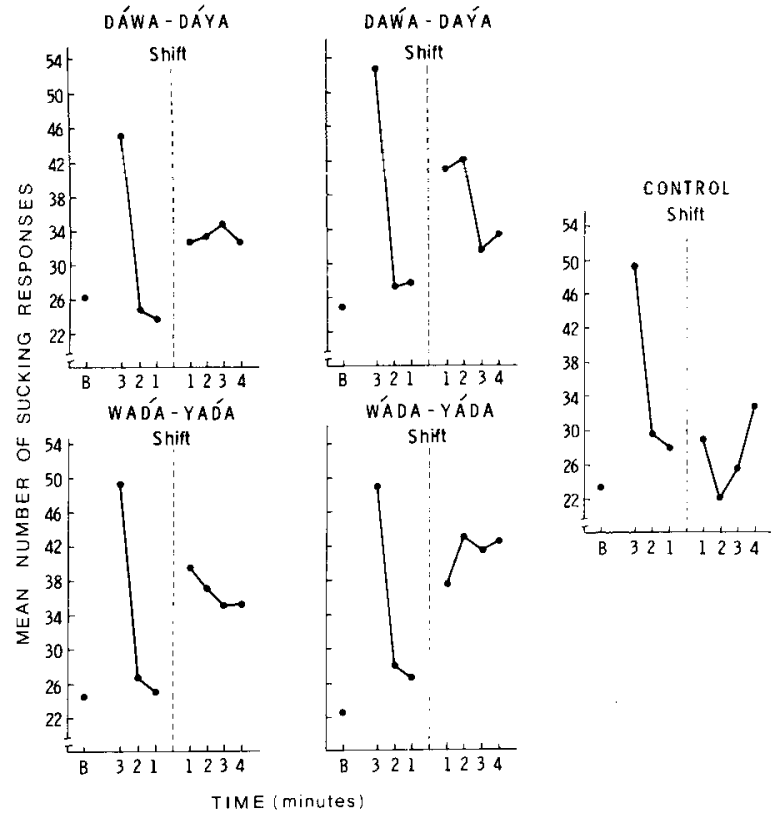

Figure 1. Mean number of high-amplitude sucking responses as a function of time and experimental group. Time is measured with reference to the moment of the stimulus shift, marked by the vertical dashed line. The baseline rate of sucking is indicated by the letter "B."

tioned high-amplitude sucking response and satiated to the first stimulus prior to shift. An indication of subjects' postshift performance is provided in Table 2 . Randomization tests for independent samples (Siegel, 1956) were used to make comparisons between each of the experimental groups (I, II, III, and IV) and the control group (V) for both the first 2 min and full 4-min periods after shift. The tests indicated reliable ( $p<.05$ or better) differences between each of the experimental groups and the control group for both the first 2 min and the full 4-min periods after shifts. Thus, the infants showed that they could discriminate between the glides in all contexts tested.

In order to determine whether the presence of stress had any effect upon the infants, we compared the postshift performance of Group I with Group II and that of Group III with Group IV. Again, randomization tests were used to make the comparisons. In neither instance was there any indication that stressed syllables were any more discriminable than unstressed ones. This finding parallels the one observed in our previous study with stop consonants in multisyllabic utterances (Jusczyk \& Thompson, 1978).

Finally, we also found no evidence that the glide contrast was any more detectable in initial position (e.g., [Wada] vs. [Yada]) than it was in medial position (e.g., [Dawa] vs. [Daya]).

\section{DISCUSSION}

The present study demonstrates that 2-month-old infants can distinguish between glides differing in place-of-articulation. Furthermore, it appears that the infant's perception of this contrast was largely unaffected by variables of position in the utterance or syllable stress. Consequently, there was no indication that infants were any less sensitive to the contrast when it occurred in the medial rather than the initial position. Nor was it true that contrasts between unstressed syllables were less discriminable than those between stressed syllables. These results directly parallel those we observed for stop consonants in multisyllabic utterances (Jusczyk \& Thompson, 1978).

There are several implications for the infant's perception of multisyllabic utterances which follow from the present findings. First of all, neither silent closure intervals nor abrupt second-syllable onsets are necessary for infants to detect phonetic contrasts in the medial position of a two-syllable utterance. While both such attributes are typically present for stimuli employing stop-consonant contrasts, glides were selected for this study precisely because they lack these attributes. Thus, given that our infants were able to discriminate glides in medial position, we are forced to reexamine Williams' (Note 6) explanation of her subjects' failure to discriminate medial stop contrasts preceded by continuous glottal pulsing. Williams hypothesized that glottal pulsing may have detracted from the abruptness of the syllable onsets, thereby making them less discriminable for her infants. While it is possible that glottal pulsing may have interacted with syllable onset in this way to produce her results, it seems, given our findings, that abrupt second-syllable onsets are not necessary per se for infants to perceive medial contrasts.

Another implication of our results is that syllable stress may have little or no effect on the infant's ability to perceive phonetic contrasts. ${ }^{3}$ This claim stands in apparent contradiction to one by developmental psycholinguists (Blasdell \& Jensen, 1970; Brown \& Fraser, 1963; Miller \& Ervin, 1964) that stress plays an important role in language acquisition. However, the task facing the 2-year-old is considerably different from that of our infants. While

Table 2

Mean Change in Response Rate After Shift

\begin{tabular}{lllr}
\hline & & \multicolumn{2}{c}{$\begin{array}{c}\text { Release From Satiation } \\
\text { (Minutes After Shift) }\end{array}$} \\
\cline { 3 - 4 } & & First 2 & Full 4 \\
\hline Group I & Dáwa-Dáya & $11.39^{*}$ & $9.00^{*}$ \\
Group II & Dawá-Dayá & $13.54^{*}$ & $9.50^{*}$ \\
Group III & Wadá-Yadá & $12.67^{*}$ & $11.06^{*}$ \\
Group IV & Wáda-Yáda & $13.08^{*}$ & $14.08^{*}$ \\
Group V & Control & -2.92 & -1.08 \\
\hline
\end{tabular}

*Indicates a reliable difference ( $p<.05$ or better) according to randomization tests when compared against performance in the Control Session. 
our infants need only detect a phonetic change, the 2 -year-old is acquiring not only the acoustic shapes of words, but word meaning and rules for combining words as well. Perhaps stress does play a role in perception in those situations in which attention is also taxed by syntactic and semantic factors, as is the case for the 2-year-old.

Glide contrasts now may be added to the growing list of distinctions that infants are capable of discriminating. ${ }^{4}$ At this juncture, we might wonder about what limits are imposed upon the speechprocessing capacities of the infant. Certainly, despite the infant's proficiency with two-syllable strings, there must be an upper limit to the length of strings which infants can process. In fact, Trehub (Note 5) found no evidence that infants could distinguish voicing contrasts between trisyllabic utterances. Whether such findings reflect a general constraint on the infant's processing abilities awaits further investigation. Regardless of what limitations are discovered, the infant has been shown to possess many of the prerequisites necessary to distinguish between a number of words. In particular, infants have the capacity to distinguish a variety of phonetic contrasts in different syllable positions and in both stressed and unstressed syllables. Thus prepared, the infant is ready to begin the task of cracking the speech code.

\section{REFERENCE NOTES}

1. Holmberg, T. L., Morgan, K. A., \& Kuhl, P. K. Speech perception in early infancy: Discrimination of fricative consonants. Paper presented at the 94th Meeting of the Acoustical Society of America, Miami Beach, December 16, 1977.

2. Hillenbrand, J., Minifie, F. D., \& Edwards, T. J. Tempo of frequency change as a cue in speech sound discrimination by infants. Paper presented at the Biennial Meeting of the Society for Research in Child Development, New Orleans, March 19, 1977.

3. Eimas, P. D., \& Miller, J. L. Personal communication, May 16, 1978.

4. Kuhl, P. K. Speech perception in early infancy: Perceptual constancy for the vowel categories $/ a /$ and $/ 2 /$. Paper presented at the 93rd Meeting of the Acoustical Society of America, State College, Pa., June 1977.

5. Trehub, S. E. Infants' discrimination of multisyllabic stimuli: The role of temporal factors. Paper presented at the annual convention of the American Speech and Hearing Association, Houston, Texas, November 21, 1976.

6. Williams, L. The effects of phonetic environment and stress placement on infant discrimination of place of stop consonant articulation. Paper presented at the Second Annual Boston University Conference on Language Development, Boston, Mass., October 1, 1977

\section{REFERENCES}

Blasdell, R., \& Jensen, P. Stress and word position as determinants of imitation in first-language learners. Joumal of Speech and Hearing Research, 1970, 13, 193-202.

Brown, R., \& Fraser, C. The acquisition of syntax. In C. N. Cofer \& B. S. Musgrave (Eds.), Verbal behavior and learning: problems and processes. New York: McGraw-Hill, 1963.

CoOper, F. S., \& Mattingly, I. G. A computer-controlled PCM system for the investigation of dichotic speech perception.
Journal of the Acoustical Society of America, 1969, 46, 115. (A)

EILERs, R. E. Context-sensitive perception of naturally produced stop and fricative consonants by infants. Joumal of the Acoustical Society of America, 1977, 61, 1321-1336.

EILERS, R. E., WILSON, W, R., \& MOORE, J. M. Fricative discrimination in early infancy. Journal of Speech and Hearing Research, 1977, 20, 766-780.

Eimas, P. D. Auditory and linguistic processing of cues for place of articulation by infants. Perception \& Psychophysics, 1974, 16, 513-521.

EImAs, P. D. Auditory and phonetic coding of the cues for speech: Discrimination of the $(r-1)$ distinction by young infants. Perception \& Psychophysics, 1975, 18, 341-347.

Eimas, P. D., Siqueland, E. R., Jusczyk, P., \& Vigortio, J. Speech perception in infants. Science, 1971, 171, 303-306.

Fry, D. B. Experiments in the perception of stress. Language and Speech, 1958, 1, 126-152.

JusCzYK, P. W. Perception of syllable-final stop consonants by 2-month old infants. Perception \& Psychophysics, 1977, 21, 450-454.

Jusczyк, P. W., \& Thompson, E. Perception of a phonetic contrast in multisyllabic utterances by 2-month old infants. Perception \& Psychophysics, 1978, 23, 105-109.

Lasky, R. E., Syrdal-Lasky, A., \& Klein, R. E. VOT discrimination by four and six and a half month old infants from Spanish environments. Joumal of Experimental Child Psychology, 1975, 20, 215-225.

McClean, M. D., \& Tiffany, W. R. The acoustic parameters of stress in relation to syllable position, speech loudness and rate. Language and Speech, 1973, 16, 283-290.

Miller, W. R., \& ERviN, S. The development of grammar in child language. In U. Bellugi \& R. Brown (Eds.), The acquisition of language. Monographs of the Society for Research in Child Development, 1964, 29, 9-35.

Miller, C., Morse, P. A., \& Dorman, M. F. Cardiac indices of infant speech perception : Orienting and burst discrimination. Quarterly Journal of Experimental Psychology, 1977, 29, 533-545.

MoRse, P. A. The discrimination of speech and nonspeech stimuli in early infancy. Journal of Experimental Child Psychology, 1972, 14, 477-492.

MoRTon, J., \& JASSEM, W. Acoustic correlates of stress. Language and Speech, 1965, 8, 159-181.

SIEGEL, S. Nonparametric statistics for the behavioral sciences. New York: McGraw-Hill, 1956.

Siqueland, E. R., \& De Lucia, C. A. Visual reinforcement of nonnutritive sucking in human infants. Science, 1969, 165, 1144-1146.

Spring, D. R., \& Dale, P. S. Discrimination of linguistic stress in early infancy. Journal of Speech and Hearing Research, 1977, 20, 224-232.

STREeTER, L. A. Language perception of 2-month old infants shows effects of both innate mechanisms and experience. Nature, 1976, 259, 39-41.

Swoboda, P. J., Morse, P. A., \& LeavitT, L. A. Continuous vowel discrimination in normal and at risk infants. Child Development, 1976, 47, 459-465.

TREHUB, S. E. The discrimination of foreign speech contrasts by infants and adults. Child Development, 1976, 47, 466-472.

\section{NOTES}

1. It should be noted that in a study involving a voicing contrast between stop consonants, Trehub (Note 5) found that contrasts occurring in medial positions were distinguished in long ( $500-\mathrm{msec})$, but not in short (300-msec), syllables. On the other hand, Jusczyk and Thompson (1978) reported discrimination of place-ofarticulation contrasts in medial positions for syllables as short as $208 \mathrm{msec}$. Of course, it is possible that longer durations may be 
required for detecting voicing contrasts than for place-ofarticulation contrasts.

2. The acoustic correlates for stress (pitch, intensity, and duration) for the present study were chosen after careful examination of a number of tokens spoken by the first author. The parameter values which were selected represent average values for the utterances by him, with the exception of the fact that some smoothing of the pitch contour was employed. It should be noted that the acoustic correlates of stress in the present study are identical to those chosen by Jusczyk and Thompson (1978).

3. Both reviewers have suggested that our conclusion that stress placement does not affect the discrimination of glides by infants may be too strong, since we did not directly test whether the infants could discriminate the stressed-unstressed distinction. Thus, one reviewer argued that if the stress cue were below threshold, then asking whether it facilitates discrimination is a wasted exercise. This point is certainly well taken. However, while we did not directly test whether infants in the present study could discriminate a stressed vs. unstressed contrast, we did do so in a previous study (Jusczyk \& Thompson, 1978). In that study, we found extremely strong support for the claim that infants are sensitive to stress differences (the mean increases in sucking rate after shift were the highest we have ever encountered and every infant tested on this contrast increased sucking after shift). Given that we used exactly the same stimulus values to create syllable stress in the present study as we did in our previous one, we have no reason to believe that our stressed-unstressed distinction was not discriminable for the present infants. Thus, while we recognize that the inclusion of stressed-unstressed distinction in the present study might have been useful as an additional control, we stand by our original conclusion, viz, that syllable stress may have little or no effect on the infant's ability to perceive phonetic contrasts.

4. The present infant study is not the first to use glides as stimuli. Hillenbrand, Minifie, and Edwards (Note 2) also used a glide in their study. However, they examined a glide ([w]) -stop ([b]) distinction, whereas we employed a place-of-articulation distinction between two glides.

(Received for publication June 19, 1978; revision accepted September 26, 1978.) 